\title{
Study of the Possible Use of a Home-Visit Nursing Interventional Lymphedema Care Program for Secondary Lymphedema in the Elderly at Home
}

\author{
Kiyomi Morimoto ${ }^{1,2}$ \\ ${ }^{1}$ Department of Nursing Science, Seisen University, Shiga, Japan \\ ${ }^{2}$ Doctoral Program, Graduate School of Nursing, Osaka Medical College, Osaka, Japan \\ Email: morimo-k@seisen.ac.jp
}

How to cite this paper: Morimoto, K. (2019) Study of the Possible Use of a Home-Visit Nursing Interventional Lymphedema Care Program for Secondary Lymphedema in the Elderly at Home. Health, 11, 1529-1541.

https://doi.org/10.4236/health.2019.1111115

Received: October 28, 2019

Accepted: November 22, 2019

Published: November 25, 2019

Copyright ( 2019 by author(s) and Scientific Research Publishing Inc. This work is licensed under the Creative Commons Attribution International License (CC BY 4.0).

http://creativecommons.org/licenses/by/4.0/

(c) (i) Open Access

\begin{abstract}
Objective: This study aimed to clarify the possible use of and points to improve a home-visit nursing interventional lymphedema care program (plan) we developed. Methods: The subjects were visiting nurses with at least three years of home-visit nursing experience and experience with lymphedema care for the elderly at home. Semi-structured interviews were conducted, and the collected opinions were aggregated and summarized. Results: Based on interviews with nine subjects, opinions regarding the use of the program, such as "The assessment perspective at the time of introduction helps to grasp the needs for a wide variety of subjects", and regarding points to improve, such as "It is necessary to set the duration and timing of the section considering the frequency of visits and degree of edema at the time of introduction" and "It is necessary to have a perspective concerning efforts to maintain motivation for care of the elderly and their families", were aggregated. Discussion: The results of the interviews were generally useful for the structure and development of the program, care methods and content, and interventions for influencing factors. Consideration of setting the timing according to the degree of lymphedema, modification of the program's development, development of a program that fully considers the degree of edema at the time of introduction and the acceptance of edema among the elderly, and the need to consider the care content that should be given priority were suggested as points for improvement.
\end{abstract}

\section{Keywords}

Elderly at Home, Secondary Lymphedema, Home-Visit Nursing, 
Lymphedema Care Program, Possible Use

\section{Introduction}

Secondary lymphedema (hereinafter abbreviated as lymphedema) develops due to lymph node dissection, etc. associated with cancer surgery, and once it develops, it is difficult to cure and must be dealt with throughout the rest of a patient's life [1] [2]. The elderly are particularly at high risk of development and deterioration of lymphedema due to muscular weakness resulting from such things as aging, hardening of skin collagen fibers, reduced elasticity of elastic fibers, and reduced immunity, etc. and long-term survival of cancer has become possible. Today, the prevalence of cancer is high in the elderly, and there are many elderly people at home who have developed lymphedema. In addition, development of lymphedema in the elderly reduces not only physical function but also affects psychosocial aspects and activities of daily living (ADL) [3], and it also results in a vicious cycle in which the decline in ADL causes symptoms to worsen, which has a great impact on quality of life (QOL).

In recent years, aging has progressed rapidly, and support with an emphasis on the QOL of elderly people is a social issue in Japan, which is a super-aged society. As the medical care delivery system shifts to the community and the integrated community care system is promoted, support for elderly people at home who have developed lymphedema is important, and home-visit nursing support that comprehensively supports the home care life of the elderly is expected. However, the support provided by home-visit nursing for elderly people with lymphedema is not sufficient because it has a variety of restrictions due to the long-term care insurance system, such as on visit time, frequency, and maximum usage fees, and it is provided in a difficult situation in which there is a lack of visiting-nurse manpower [4].

According to a previous study about the practice of lymphedema care in home-visit nursing, lymphedema care that takes advantage of countermeasures for the disadvantages of elderly people and the strengths of home-visit nursing is being practiced based on formal and informal support that supports the elderly and mutual relationships of trust with visiting nurses, and as a result, returning to desired jobs and spending quality time as a couple were realized. On the other hand, it was also clarified that there were problems in terms of restrictions on home-visit nursing systems and team care in lymphedema care [5]. Therefore, based on these results, we developed a lymphedema care program aimed at solving the problems by utilizing the characteristics of home-visit nursing care and improved it so that it could be used to prevent the deterioration of lymphedema and realize a life that maintains ADL and QOL.

The purpose of this study was to evaluate whether the Home-Visit Nursing Intervention Lymphedema Care Program (plan) devised based on the research results of Morimoto and Akazawa [5] can be used as a program for solving the 
problems by utilizing the characteristics of home-visit nursing care and as a lymphedema care program for the elderly at home by visiting nurses, and to identify points to improve.

The Home-Visit Nursing Intervention Lymphedema Care Program (plan) developed in this study (hereinafter referred to as the "program plan") was a program practiced by visiting nurses for elderly people requiring nursing care, and the purpose of the program was to make it possible to provide lymphedema care that leads to maintenance of $\mathrm{ADL}$ and QOL in elderly people receiving care at home. Based on the results of a previous study [5], seven component elements were extracted, and a program framework (Figure 1) was created based on relationships among these elements. Nursing perspectives and support contents are shown in Table 1. With reference to previous studies [6], the program's intervention period was divided into three sections, and specific goals and evaluation periods were set for each. The contents and methods of lymphedema care in each section are shown in Table 2 . In addition, a home lymphedema care practice guide (hereinafter referred to as the "practice guide") was prepared in order to implement the program effectively. The background and purpose of the program were briefly described, and nursing perspectives and support methods, the program's flow, and specific goals, care contents, and support methods in each section were presented in the practice guide.

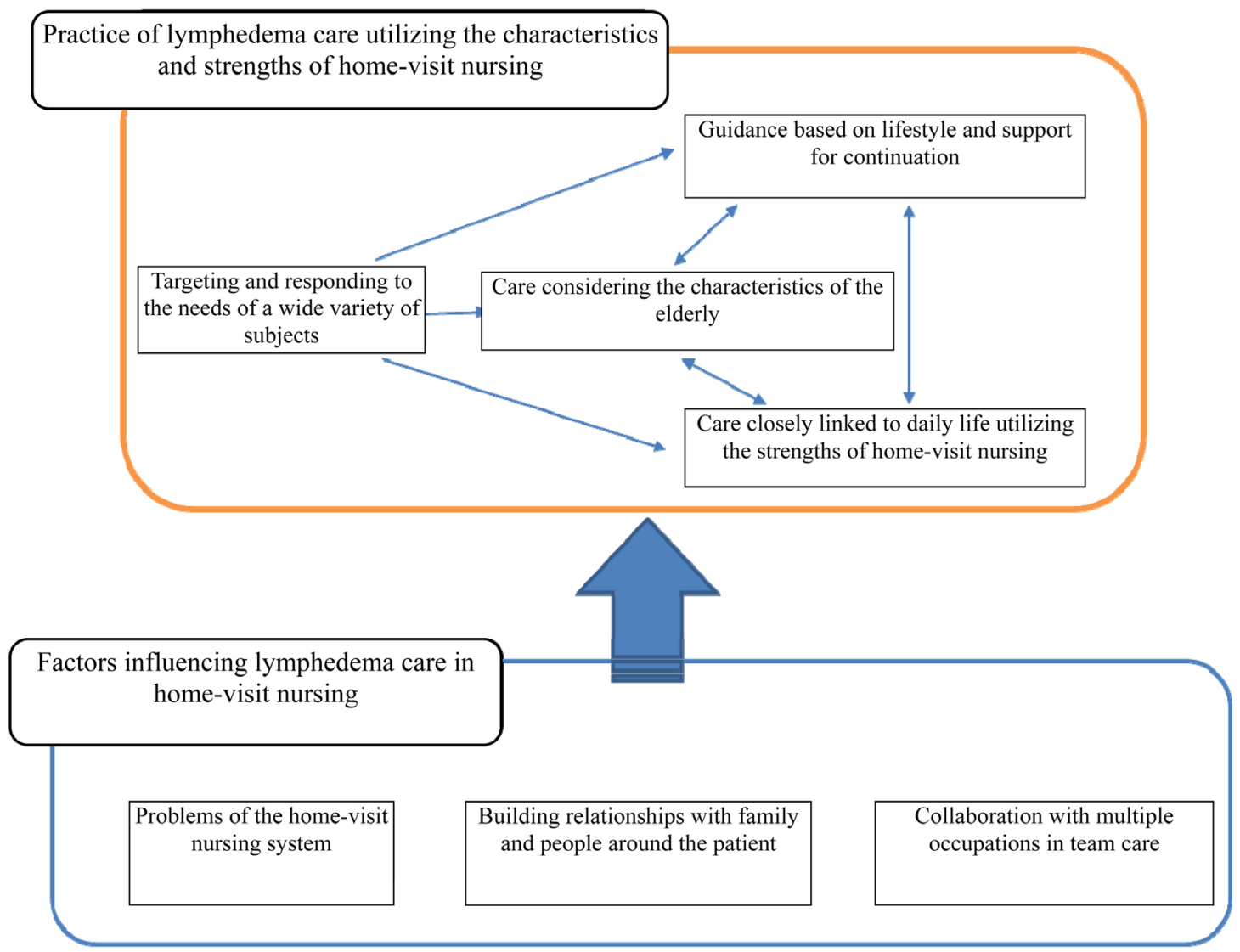

Figure 1. Framework of the home-visit nursing intervention lymphedema care program (plan). 
Table 1. Perspectives of nursing support and support content.

\begin{tabular}{|c|c|}
\hline Perspectives of nursing support & Support contents \\
\hline $\begin{array}{l}\text { Targeting and responding to the needs of a } \\
\text { wide variety of subjects }\end{array}$ & $\begin{array}{l}\text { Assessing not only the stage of lymphedema but also physical function (aging changes), lifestyle } \\
\text { background, needs for care through home-visit nursing, housing environment, etc. }\end{array}$ \\
\hline $\begin{array}{l}\text { Care considering the characteristics of the } \\
\text { elderly }\end{array}$ & $\begin{array}{l}\text { Providing care not focusing on the characteristics of the elderly as disadvantages but instead } \\
\text { focusing on the abilities of the elderly who have a lifestyle that they have devised in their life. }\end{array}$ \\
\hline $\begin{array}{l}\text { Guidance based on lifestyle and support for } \\
\text { continuation }\end{array}$ & $\begin{array}{l}\text { Providing guidance on daily life considerations in accordance with individual family backgrounds } \\
\text { and lifestyles and providing support to keep up with daily life considerations. }\end{array}$ \\
\hline $\begin{array}{l}\text { Care closely linked to daily life utilizing the } \\
\text { strengths of home-visit nursing }\end{array}$ & $\begin{array}{l}\text { Care focusing on the "strengths" of home-visit nursing that enables visiting nurses to get a direct } \\
\text { understanding of a patient's life at home and values care practices with an approach to life. }\end{array}$ \\
\hline $\begin{array}{l}\text { Building relationships with family and people } \\
\text { around the patient }\end{array}$ & $\begin{array}{l}\text { Informal support (such as cooperation of family, relatives, friends in the neighborhood, and the } \\
\text { community and public support centered on nursing care insurance services that support the } \\
\text { elderly) and support for building good relationships. }\end{array}$ \\
\hline $\begin{array}{l}\text { Collaboration with multiple occupations in } \\
\text { team care }\end{array}$ & $\begin{array}{l}\text { Mitigating differences in the degree of understanding of care for lymphedema among multiple } \\
\text { occupations and striving to devise collaboration methods, understand one another, and make } \\
\text { adjustments. }\end{array}$ \\
\hline Problems of the home-visit nursing system & $\begin{array}{l}\text { Establishing a system that can be delegated to other occupations, utilizing the power of the family, } \\
\text { and improving lymphedema care skills of visiting nurses in environments in which the visit time } \\
\text { and frequency are limited and it is considered difficult to provide adequate lymphedema care. }\end{array}$ \\
\hline
\end{tabular}

Table 2. Home-visit nursing intervention lymphedema care program (plan).

Program goal + AI: E8

Can prevent the decline of ADL and deterioration that are characteristic of elderly people at home and maintain and improve QOL by providing effective interventions that make use of the characteristics of home-visit nursing to home-aged elderly who have developed lymphedema

\begin{tabular}{|c|c|c|c|c|}
\hline \multirow[b]{3}{*}{ 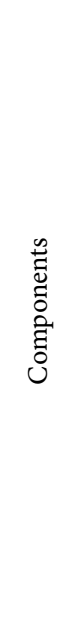 } & \multirow[b]{2}{*}{ Intervention period } & First Section & Second Section & Third Section \\
\hline & & $\begin{array}{l}\text { From after the introduction decision } \\
\text { to the start of the intervention. } \\
\text { (Implement at first visit or first } \\
\text { lymphedema care). }\end{array}$ & $\begin{array}{l}\text { From the start of the intervention to } 1 \\
\text { month later. } \\
\text { (Implement at a visit after around } 1 \\
\text { month). }\end{array}$ & $\begin{array}{l}\text { From the start of the intervention to } 3 \\
\text { months later. } \\
\text { (Implement at a visit after around } 3 \\
\text { months). }\end{array}$ \\
\hline & Specific goals & $\begin{array}{l}\text { - Understand the background of the } \\
\text { introduction of lymphedema care at } \\
\text { home and consider ways to meet } \\
\text { diverse needs. } \\
\text { - Determine care contents and } \\
\text { methods possible within the visit } \\
\text { time. } \\
\text { - Respond to the patient's various } \\
\text { needs and create a foothold for } \\
\text { building trust. }\end{array}$ & $\begin{array}{l}\text { - Consider and provide guidance for } \\
\text { the aggravating factors of } \\
\text { lymphedema in daily life and for } \\
\text { specific improvements in accordance } \\
\text { with lifestyle. } \\
\text { - Understand the strengths of the } \\
\text { patient and the disadvantages of being } \\
\text { elderly and devise care methods that } \\
\text { can maximize their strengths. }\end{array}$ & $\begin{array}{l}\text { - Provide guidance that motivates the } \\
\text { person to continue life with attention to } \\
\text { prevention of the deterioration of } \\
\text { lymphedema. } \\
\text { - Devise and practice sustainable care } \\
\text { methods with emphasis on the life of } \\
\text { the person. } \\
\text { - Coordinate the support of multiple } \\
\text { occupations, families, and surrounding } \\
\text { people to relieve anxiety during periods } \\
\text { without a home nurse present. }\end{array}$ \\
\hline 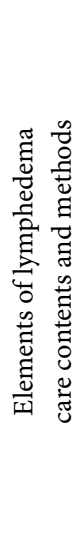 & $\begin{array}{l}\text { Targeting and } \\
\text { responding to the } \\
\text { needs of a wide } \\
\text { variety of subjects }\end{array}$ & $\begin{array}{l}\text { * Understanding of the physical } \\
\text { condition: Know the location and } \\
\text { extent of the underlying disease and } \\
\text { lymphedema and assess the care } \\
\text { contents and methods. } \\
\text { * Acceptance of lymphedema and } \\
\text { thoughts about care. } \\
{ }^{\star} \text { Know the process of introducing } \\
\text { home-visit nursing and the care } \\
\text { that the patient wants for } \\
\text { home-visit nursing and assess the } \\
\text { priority of care. }\end{array}$ & $\begin{array}{l}{ }^{*} \text { Evaluate changes caused by an } \\
\text { intervention by measuring the } \\
\text { circumferences of lymphedema sites. } \\
{ }^{*} \text { Present points to keep in mind according } \\
\text { to the site and severity of lymphedema } \\
\text { and consider implementation goals } \\
\text { together with the patient. } \\
{ }^{*} \text { Give specific guidance on points to } \\
\text { keep in mind in daily life in order to give } \\
\text { priority to the care desired by the patient } \\
\text { during the visit. } \\
{ }^{*} \text { Devise care methods that are possible } \\
\text { with home-visit nursing, since the same } \\
\text { methods as used in hospitals are difficult } \\
\text { in terms of time. }\end{array}$ & $\begin{array}{l}{ }^{*} \text { Evaluate changes due to interventions } \\
\text { by measuring the circumferences of } \\
\text { lymphedema sites. } \\
{ }^{*} \text { Consider methods that allow users to } \\
\text { recognize and express increases or } \\
\text { decreases in the severity of } \\
\text { lymphedema. } \\
\text { * Provide information about appropriate } \\
\text { care methods according to the severity } \\
\text { of lymphedema, have the patient choose } \\
\text { them, and make compromises with } \\
\text { respect to the care desired by the pa- } \\
\text { tient. }\end{array}$ \\
\hline
\end{tabular}


* Assess the contents and methods of lymphedema care based on age-related changes (skin tissue Care considering the changes and decline of immunity, characteristics of the muscle strength, and cognition) and elderly the status of ADL.

${ }^{*}$ Know the patient's motivation to live after the experience of a loss and assess self-care motivation.
Guidance based on lifestyle and support for continuation
${ }^{*}$ Know the time to onset after surgery and the lifestyle until onset. * Assess the contents of lymphedema care during hospitalization and whether they can be continued at home.
* Know the living environment Care closely linked to (house/room) and lifestyle and daily life utilizing the assess the impact on lymphedema. strengths of $\quad$ * Life problems caused by home-visit nursing lymphedema and self-coping methods.
* Observe the skin and keep it moisturized after the cleanliness care desired by the patient.

* Explain self-drainage again, since patients often do not remember the guidance provided during hospitalization.

* Select elastic clothing suitable for weak skin and reduced grip strength and consider methods for putting it on and taking it off with the patient to encourage wearing it.

* Discover complications such as lymphatic leakage earlier, maintain cleanliness, and prevent infection. ${ }^{*}$ If the patient's skin is itchy, keep it moisturized and provide nail care to prevent wounds. put into practice points to keep in mind in daily life without changing the lifestyle the patient has had up to then.

* Know about dietary habits, hygiene habits, and preferences with respect to clothes to wear. If they are factors in the deterioration of lymphedema, consider how to improve them. * Provide encouragement and praise for continuation.

* Arrange the environment around sofas and beds for daily life so that patients can relax.

* If the structure of the house or layout of the furniture is a factor in the deterioration of lymphedema, work with the patient to consider and implement improvements.

* Propose exercises that can be done in daily life, such as cleaning and washing clothes.
* Consider with the patient ways to

* Pay attention to diseases characteristic of the elderly, such as osteoporosis and heart failure, and consider methods and frequencies with the patient to avoid overloading them.

* If it is difficult for the patient to put on and take off clothes or it is difficult for the family alone to provide support, choose easy-to-wear elastic clothing and encourage the patient to wear it according to his/her lifestyle rhythm. * Recognize the accumulation of daily efforts and small efforts and provide praise while accepting that they were "bothersome" or "forgotten".

* Encourage the patient to incorporate family and work together with them on exercises the patient was good at.

* If the patient experiences skin problems caused by hobbies or housework, devise countermeasures, such as protecting the skin, instead of discontinuing the activities.

* During visits, check the self-drainage technique in conjunction with the performance of visiting-nurse manual lymph drainage.

* Do not disallow daily self-drainage; instead, teach how to comply with the manual when visiting.

* Predict the looseness of elastic bandages from the level of household tasks (range of behavior) and consider who will take on the role of removing the bandages based on the lifestyle rhythm.

* If the patient has over-the-counter drugs (such as ointments) that are used regularly, check the application and provide guidance on how to use them.

* Build a relationship of trust by

* Show points to keep in mind in daily devising methods (touch and massage) life while envisioning life with family that can make the time peaceful during or living alone.

* Implement support with the fight difficult situations.

whether or not there are famil members or caregivers, and other motivation to

relationships with surrounding people and assess their family and people care abilities.

around the patient ${ }^{*}$ Know the relationships with care managers and assess their management abilitie. patient is able to continue, provide difficult for a patient to accept care the praise and help the patient to next time, cooperation with nursing continue, and also provide support to care should be assessed, obtained, and get help so that the burden does not implemented. increase.
${ }^{*}$ Respond to family concerns when skin problems occur. 


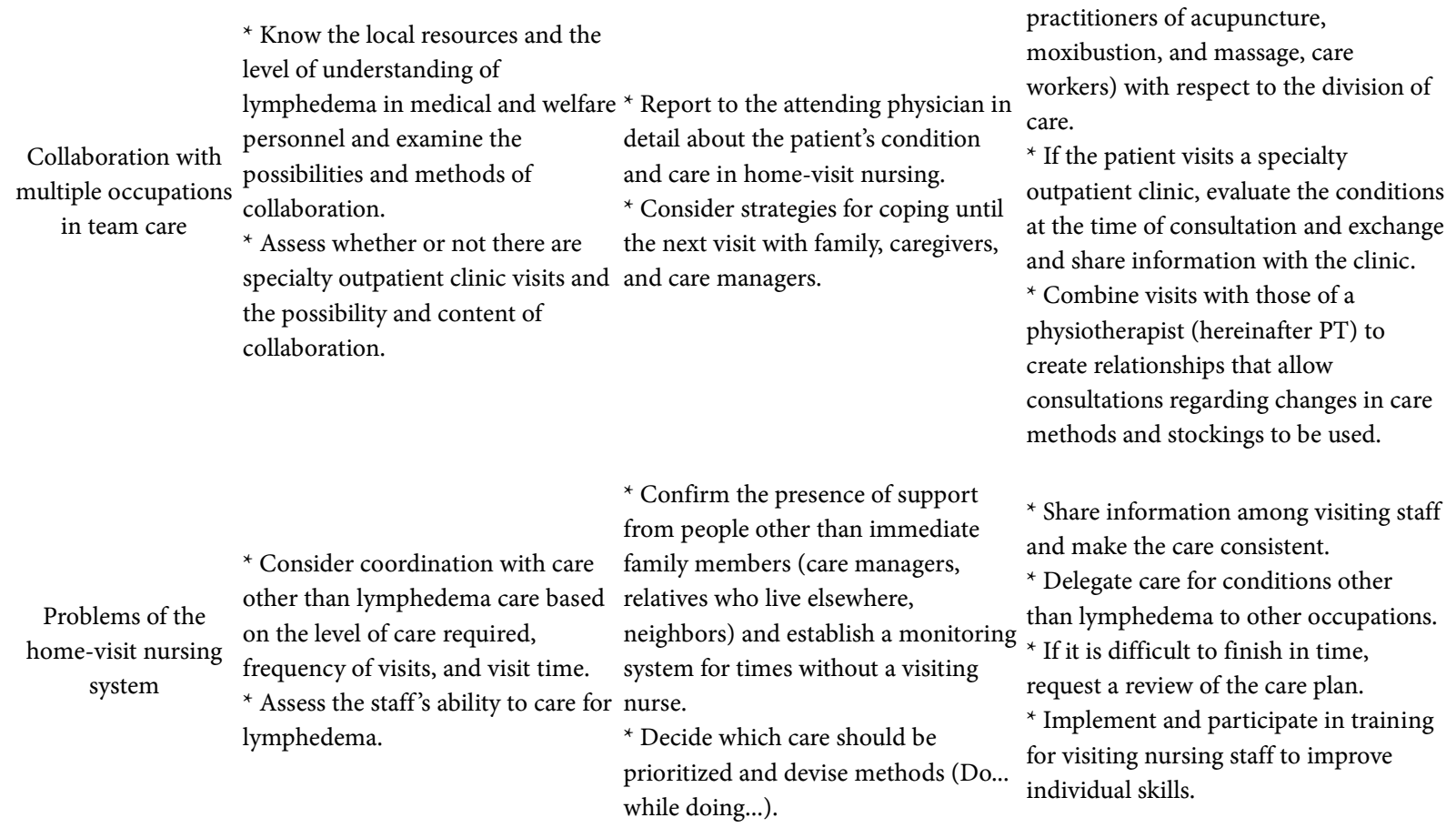

\section{Methods}

1) Definition of terms

In this study, "elderly people at home" was defined as people who were 65 years of age or older who were certified as needing support/care required by long-term care insurance and were treated at home using home-visit nursing services, and "lymphedema care" was defined as a combined therapy provided as a conservative treatment for lymphedema, meaning complex physical therapy (skin care, manual lymph drainage, compression therapy with elastic bandages and clothes, exercise therapy under pressure) and daily life guidance.

2) Subjects

The subjects were visiting nurses who worked at home-visit nursing stations that provided lymphedema care for the elderly at home and were recommended by their managers, had 3 or more years of experience in home-visit nursing, had experience in lymphedema care for the elderly at home, and agreed to participate in the study. I requested a recommendation from nurse who participated in a previous study.

3) Study methods

For data collection, a care practice guide was presented to the recommended visiting nurses by mail. Then, the visiting nurses provided lymphedema care 2 3 times for elderly people over the age of 65 who had developed lymphedema, referring to the practice guide they had received. After providing care 2 - 3 times, an interview schedule was set, and interviews were conducted. The inter- 
views were about how lymphedema care was carried out with reference to the practice guide, what contents were particularly useful, and what points should be improved for continued use in the future.

4) Analysis methods

In order to clarify the program plan's applicability and points to improve, verbatim records of the interviews were created for each subject, and each subject's comments regarding the applicability and points to improve were extracted as they were; concise sentences that did not impair the meaning of the extracted text were generated, and similar opinions and contents were aggregated and expressed as contents that clarified the applicability and points to improve. The reliability and validity of the analysis were ensured by supervising nursing researchers who read the verbatim records carefully and were familiar with lymphedema care.

\section{Results}

1) Overview of the subjects

The subjects were 9 visiting nurses working at home-visit nursing stations; three of them were in their 50s, three of them were in their $40 \mathrm{~s}$, and three of them were in their 30s. The average number of years of nursing experience was 20.6 years (10 to 40 years), and the average number of years of visiting-nurse experience was 9.6 years ( 3 to 20 years). Four of them had qualifications as lymphedema therapists or other qualifications.

2) Results of analysis

The opinions of visiting nurses who practiced lymphedema care regarding applicability and points to improve the program and the practice guide were summarized as follows (shown in Table 3):

a) Program objectives, goals, and development

Regarding applicability, opinions such as "Evaluation and correction of nursing plans become concrete" and "Goals are set based on the characteristics of home-visit nursing such as the approach to daily life" were summarized as "Goals are specific and useful for evaluating and adjusting nursing plans". Opinions such as "You can continue the care into the next section by performing evaluations over time" and "Circumference measurements are necessary as an index to continue care for lymphedema" were summarized as "Evaluating each section can lead to care in the next section". Regarding points to improve, opinions such as "Evaluations are difficult to perform in one month, depending on the frequency of visits and the severity of lymphedema at the time of introduction", "Although evaluations are performed at 1 month or three months after introduction, I feel that the lives of users have a longer cycle", and "After three months, we are monitoring interventions for evaluations every six months" were summarized as "It is necessary to set the period and time of a section in consideration of the frequency of visits and the severity of lymphedema at the time of introduction". 
Table 3. Summary of opinions concerning the program plan's applicability and points to improve.

\begin{tabular}{|c|c|c|}
\hline & Summaries of opinions about applicability & Summaries of opinions about points to improve \\
\hline \multirow[t]{2}{*}{$\begin{array}{l}\text { Program objectives, goals, and } \\
\text { development }\end{array}$} & $\begin{array}{l}\text { Goals are specific and useful for evaluating and } \\
\text { adjusting nursing plans. }\end{array}$ & $\begin{array}{l}\text { It is necessary to set the period and time of a } \\
\text { section in consideration of the frequency of visits } \\
\text { and the severity of lymphedema at the time of } \\
\text { introduction. }\end{array}$ \\
\hline & $\begin{array}{l}\text { Evaluating each section can lead to care in the } \\
\text { next section. }\end{array}$ & \\
\hline \multirow[t]{3}{*}{$\begin{array}{l}\text { Utilization of the contents and methods of } \\
\text { lymphedema care in this program }\end{array}$} & $\begin{array}{l}\text { The assessment perspective at the time of } \\
\text { introduction helps to understand the needs for a } \\
\text { wide variety of subjects. }\end{array}$ & $\begin{array}{l}\text { It is important to identify the situation at the time } \\
\text { of introduction to respond to various needs. }\end{array}$ \\
\hline & $\begin{array}{l}\text { It is good that the abilities of the elderly are } \\
\text { determined and that the perspective of support } \\
\text { not being forced is shown. }\end{array}$ & $\begin{array}{l}\text { A perspective on how to maintain motivation for } \\
\text { care in the elderly and their families is necessary. }\end{array}$ \\
\hline & $\begin{array}{l}\text { This program uses the characteristics of } \\
\text { home-visit nursing to focus on adjustment of the } \\
\text { living environment. }\end{array}$ & $\begin{array}{l}\text { It is important to show adjustment of the living } \\
\text { environment, including the social environment, as } \\
\text { a viewpoint. }\end{array}$ \\
\hline \multirow[t]{6}{*}{$\begin{array}{l}\text { Utilization of interventions for factors } \\
\text { affecting lymphedema care in home-visit } \\
\text { nursing }\end{array}$} & $\begin{array}{l}\text { Collaboration with the attending physician and } \\
\text { ward/outpatient nurses through summaries is } \\
\text { effective. }\end{array}$ & $\begin{array}{l}\text { Interventions that require specialized knowledge } \\
\text { and skills require a perspective of cooperation } \\
\text { with outpatient departments and therapists. }\end{array}$ \\
\hline & & $\begin{array}{l}\text { The intervention methods for problems of the } \\
\text { home-visit nursing system should show the } \\
\text { problem items concretely. }\end{array}$ \\
\hline & & $\begin{array}{l}\text { It is necessary to indicate the priority care in each } \\
\text { section depending on the state of lymphedema. }\end{array}$ \\
\hline & & $\begin{array}{l}\text { It would be better to have descriptions regarding } \\
\text { the understanding and skills of complex } \\
\text { treatment. }\end{array}$ \\
\hline & & $\begin{array}{l}\text { It is better for things such as assessment tools and } \\
\text { lymphedema evaluation guides to be shown } \\
\text { concretely. }\end{array}$ \\
\hline & & $\begin{array}{l}\text { The size of the guide and the text in it are small } \\
\text { and difficult to read, and there are overlapping } \\
\text { parts in the care contents. }\end{array}$ \\
\hline
\end{tabular}

b) Utilization of the contents and methods of lymphedema care in this program

Opinions such as "It is good that the perspective of assessments is shown in detail" and "At the time of introduction, I thought I was collecting information from this perspective" were summarized as "The assessment perspective at the time of introduction helps to understand the needs for a wide variety of subjects". Regarding points to improve, opinions such as "It is necessary to identify the priority of the care based on the severity of lymphedema and the level of care required" and "It is necessary to identify the trigger for introduction of care and the state of lymphedema at the time of introduction to respond to care needs" were summarized as "It is important to identify the situation at the time of introduction to respond to various needs". 
Opinions such as "In compression therapy, a method of determining the extent to which it can be conducted by a patient is proposed" and "I felt that this program places importance on, to the extent possible, not forcing compliance" were summarized as "It is good that the ability of an elderly person is determined and that the perspective of support not being forced is shown".

Regarding points to improve, opinions such as "Circumference measurements alone can lead to discontinuation of care if there are no dramatic changes in evaluation" and "How to maintain motivation is important because care will be provided while the patient is depressed by the onset of lymphedema" were summarized as "A perspective on how to maintain motivation for care of the elderly and their families is necessary".

Opinions such as "The state of lymphedema is checked by the ease of going up and down stairs and going to the toilet" and "A patient's life can be seen only after an intervention by visiting nursing. I think that a perspective that visualizes the patient's life is good in home-visit nursing" were summarized as "This program uses the characteristics of home-visit nursing to focus on adjustment of the living environment". Regarding points to improve, opinions such as "The living environment may change as a result of moving or living with a daughter during an intervention, and stress may lead to deterioration of lymphedema" were summarized as "It is necessary to show adjustment of the living environment, including the social environment, as a viewpoint".

c) Utilization of interventions for factors affecting lymphedema care in home-visit nursing

Opinions such as "At the time of introduction, summaries are an important tool in this kind of collaboration" were summarized as "Collaboration with the attending physician and ward/outpatient nurses through summaries is effective". Regarding points to improve, opinions such as "In compression therapy, I think it is particularly difficult for visiting nurses to get patients to choose and purchase elastic clothes and to explain to them how to buy them" and "Choosing elastic clothing is difficult unless you are working with a lymphedema outpatient department" were summarized as "Interventions that require specialized knowledge and skills require a perspective of cooperation with outpatient departments and therapists".

Opinions such as "In order to carry out necessary care with limited visit time, there are times when the use of medical insurance is recommended" and "I am often told that it is difficult financially" were summarized as "The intervention methods for problems of the home-visit nursing system should show the problem items concretely". Opinions such as "Since it was a user who had cellulitis repeatedly, I first provided careful instructions for skin care" and "Because the patient was elderly and had lymphedema that impacted his/her life, compression therapy was provided first when I visited twice a week" were summarized as "Within a limited time, it is necessary to indicate priority care in each section depending on the state of lymphedema". Opinions such as "Regarding skin care and compression therapy in complex physical therapy, they are difficult unless 
one's understanding extends to even specialized parts" and "Because it is very difficult to understand the pathophysiology of secondary lymphedema, it is better to describe it in the guide" were summarized as "It would be better to have descriptions regarding the understanding and skills of complex physical therapy". In addition, opinions such as "Since everyone does not have the same level of knowledge, there is a need for measures to provide uniform care" and "I understand the perspective of assessment, but I want tangible items, such as tools, concerning how to connect assessments to care" were summarized as "It is better for things such as assessment tools and lymphedema evaluation guides to be shown concretely".

\section{Discussion}

1) Program structure and development

The objectives, goals, and setting of the sections of the program were roughly appropriate, and it can be said that the program can be used for lymphedema care in home-visit nursing. However, the third section was about 1 to 3 months after the introduction of interventions, and evaluations were scheduled for visits 3 months later, but it was not possible to set up subsequent evaluations for elderly people who needed long-term management. The success or failure of long-term management is said to depend on the link between the continued use of compression therapy and self-care implemented under specialized complex treatment and appropriate guidance. Success results in the improvement of body image and recovery of physical function, leading to improved quality of life [7]. Therefore, we believe that it is necessary to consider the timing and interval and to show them concretely in the third section. Furthermore, we believe that the development of the program needs to be modified to improve the setting of the timing based on the severity of lymphedema.

2) Possibilities and improvements of the utilization of contents and methods of lymphedema care

As summarized in "It is important to identify the situation at the time of introduction to respond to various needs", there are a variety of situations in which visiting-nurse interventions begin, such as when a request is made by a doctor at a hospital, when a request is made by a care manager, or when lymphedema develops while already using home-visit nursing for nursing-care needs. Therefore, the severity of lymphedema at the time of introduction of interventions varies. Accordingly, the methods of understanding lymphedema and care needs of patients are different, and the necessary and prioritized support and care are also different. Masujima and Sato [8] did not consider support for coping behavior to minimize the deterioration of lymphedema, as it has little impact on life until Stage I. As for care, they reported that promotion of the understanding of lymphedema in order to continuously eliminate aggravating factors and accept the development of lymphedema and provision of support to continue preventive action represent important support and that in Stage II and 
later, actions such as seeking knowledge about lymphedema and facilities for specialized treatment were taken to prevent deterioration. This suggests that it is necessary to promote early awareness of signs of deterioration of lymphedema due to the need for complex treatment and continuation of such treatments. In order to fully respond to the needs of the elderly at home, it is necessary to consider the severity of lymphedema at the time of introduction of interventions and the acceptance of lymphedema and to examine the development of the program and the contents of care in the elderly in this program.

As summarized by "It is good that the abilities of the elderly are determined and that the perspective of support not being forced is shown", it is considered again that care provided from the perspective of the strengths of the elderly was supported. Therefore, it was suggested that there is a need for a medium that respects the strengths of the elderly in their lifestyles and can be used by both the patient and people who provide living support, such as nurses to prevent the deterioration of lymphedema and to continue lymphedema care. In addition, as a point to improve, it was suggested that "A perspective on how to maintain motivation for care in the elderly and their families is necessary". That is, it is necessary to consider the addition of evaluation items that allow lymphedema care to be incorporated into daily life in order to maintain the motivation for continuing lymphedema care and the addition of evaluation items that are not only objective indicators but also evaluation items (life goals) for the life desired by the person.

As indicated by the point to improve "It is important to show changes in the living environment including the social environment as a viewpoint", changes in the living environment, such as moving during an intervention or living with a daughter, and the resulting stress may lead to deterioration of lymphedema. Because they are visiting nurses, they are able to consider the situations of families and the connection with the severity of lymphedema; therefore, it is considered necessary to add psychological measures and consultation support for elderly families to the support contents so that psychological changes and stress do not adversely affect lymphedema care.

3) Possibilities and improvements of the utilization of interventions for factors affecting lymphedema care in home-visit nursing

Regarding the practice of lymphedema care in home-visit nursing, this program presented the types of occupations, timings, and methods for cooperation with the aim of smooth cooperation and team care. However, as indicated by the point to improve "Interventions that require specialized knowledge and skills require a perspective of cooperation with outpatient departments and therapists", it was shown once again that when visiting nurses were not confident in their knowledge and skills regarding lymphedema care, especially the selection of elastic clothing for compression therapy, they were coping by cooperating with specialist outpatient clinics and visiting nurses with therapist qualifications. In addition, it was suggested that care must give priority to the needs of the in- 
dividual and family because it is restricted to a limited amount of time. However, no specific measures were shown in this program for such difficult decisions [4]. Therefore, it is considered necessary to present the support and care that should be prioritized according to the state of lymphedema and care needs in each section. In addition, in order to respond to the lack of confidence in knowledge and skills of individual visiting nurses in lymphedema care and to put lymphedema care into practical use through this program, it seems necessary to include such things as tools and evaluation guides that present basic knowledge and specific contents in the practice guide.

\section{Conclusions}

Examination of the program plan's applicability and points to improve suggested that the contents and development of the program, care methods and contents, and interventions for influencing factors could be used in general in the practice of lymphedema care for the elderly at home by visiting nurses. On the other hand, the following were also indicated as points for improvement:

- Modify the development of the program by improving the setting of the timing according to the severity of lymphedema.

- Examine the development of the program and the contents of care and make additional adjustments to the program plan with careful consideration of the severity of lymphedema at the time of introduction of interventions and acceptance of lymphedema in the elderly.

- Add evaluation items that allow lymphedema care to be incorporated into daily life in order to maintain motivation in the patient for continuing lymphedema care and evaluation items that are not only objective indicators but also evaluation items (life goals) for the life desired by the person.

- Add psychological measures and consultation support for elderly families to the support contents so that the psychological changes and stress do not adversely affect lymphedema care.

- Present support and care that should be prioritized according to the state of lymphedema and care needs in each section.

- Include such things as tools and evaluation guides that present basic knowledge and specific contents in the practice guide.

\section{Support}

This study was conducted with support from the France Bed Medical Home Care Research Subsidy Foundation in 2019.

\section{Conflicts of Interest}

The author declares that there are no conflicts of interest in this study.

\section{References}

[1] Shoten, N. (2011) Easy-to-Understand: All about Lymphedema. In: Mitsushima, I., 
Ed., Anatomy and Physiology to Conservative Treatment and Surgical Treatment, Nagai Syoten, Osaka, 1-2, 102-104.

[2] Onishi, Y. (2016) Care for Lymphedema in Cancer Patients. Nursing Skills, 62, 10.

[3] Nakamura, S. and Kamizato, M. (2010) The Coping Behaviors on Physical and Psychosocial Distress of Daily Living among Breast Cancer Patients with Lymphedema. Journal of Okinawa Prefectural College of Nursing, 11, 1-13.

[4] Morimoto, K. (2017) A Study on Nursing Intervention by Visiting Nurses for the Elderly at Home with Secondary Lymphedema. Yumi Foundation Home Health Care Grant, Report 2017.

[5] Morimoto, K. and Akazawa, C. (2019) Practice of Secondary Lymphedema Care for Elderly at Home by Visiting Nurses. Osaka Medical College Journal of Nursing Research, 9, 115-122.

[6] The National Association for Visiting Nurse Service (2002) Research Project for Development of Care Management for Home Care of Children. In: The Project Promotion Review Committee, Ed., Care Management Program for Children and Their Families Performing Home Ventilator Therapy, 2nd Edition, Tokyo, 1-12.

[7] Kitamura, K (2014) Clinical Guidelines for Lymphedema. In: Japan Lymphedema Study Group, Ed., Kanehara Syuppan, Tokyo, 16.

[8] Masujima, K. and Sato, R. (2008) How to Understand and Cope with Lymphedema in Patients Who Developed Lymphedema after Breast Cancer Surgery. Journal of Chiba Academy of Nursing Science, 14, 17-25. 